\title{
Thermal Modelling of the Torrefaction Process Using the Finite Element Method
}

\author{
Alok DHAUNDIYAL ${ }^{1 *}$, Laszlo TOTH ${ }^{2}$ \\ ${ }^{1,2}$ Institute of Process Engineering, Szent Istvan University, Godollo, Hungary
}

\begin{abstract}
This paper focuses on the thermal characteristic of the torrefied pinecone pellets. The resistivity heating system was used for torrefaction purposes. The torrefaction was conducted at $523 \mathrm{~K}$ for different holding times of 5,10 and 15 minutes. The thermal behaviour of the pinecone pellet was numerically predicted using the pdepe algorithm. A parabolic 2-D heat transfer equation was used to estimate the thermal profile across the pinecone. The effect of the interactive atmosphere was on the numerical solution was also examined. The pelletisation was performed using a ring-die at the temperature of $70{ }^{\circ} \mathrm{C}$.
\end{abstract}

Keywords - Finite element analysis; heat transfer; pellet, thermal; torrefaction

\begin{tabular}{|lll|}
\hline Nomenclature & & \\
$C$ & Specific heat of material & $\mathrm{kJ} \cdot \mathrm{kg}^{-1} \cdot \mathrm{K}^{-1}$ \\
$h$ & Heat transfer coefficient & $\mathrm{kJ} \cdot \mathrm{m}^{-2} \cdot \mathrm{K}^{-1}$ \\
$\rho_{\mathrm{b}}$ & Thermal conductivity of the material & $\mathrm{kJ} \cdot \mathrm{m}^{-1} \cdot \mathrm{K}^{-1}$ \\
$\rho_{\mathrm{m}}$ & Bulk density & $\mathrm{kg} \cdot \mathrm{m}^{-3}$ \\
$N u$ & Material density & $\mathrm{kg} \cdot \mathrm{m}^{-3}$ \\
$R e$ & Nusselt's number & - \\
$H H V$ & Reynold's number & - \\
$T T_{e x t}$ & Higher heating value & $\mathrm{MJ} \cdot \mathrm{kg}^{-1}$ \\
$T$ & Furnace temperature & $\mathrm{K}$ \\
$L$ & Temperature of the pellet & $\mathrm{K}$ \\
\hline
\end{tabular}

\section{INTRODUCTION}

Generally, the torrefaction of biomass is carried out using a microwave-based reactor. This technique requires varying power and frequency. That eventually causes an uneven thermal pre-treatment due to intermolecular friction within the structure. A drawback pertaining to micro-wave restricts its utilisation for the limited period [1]. Some studies on micro-wave torrefaction were conducted and it was reported that energy yield of municipal waste and Leucaena was surged by $21 \%$ and $7 \%$, respectively, but the effect of thermal condition on the material behaviour was omitted [2]. In another study on Lemongrass, the torrefaction was performed at $200-300{ }^{\circ} \mathrm{C}$, which consequently, increased the carbon by $124 \%$. The obtained biochar was later densified with the help of binding agent, starch [3].

*Corresponding author.

E-mail address: alok.dext@hotmail.com 
But overall process merely increased the cost of production and the torrefaction technique was performed without considering effect of temperature distribution on the material. The similar kind of technique was conducted for wet torrefaction of microalgal hydrolysate. The narrow range of temperature was used for holding time of 5-10 minutes, but the effect of thermal condition on the productivity of bioethanol was overlooked [4]. The agro-based residue char was used as an absorber to undermine the effect of microwave irradiance on MSW. The concept of addition of bagasse char fairly worked, but the overall change in fixed carbon was nearly constant [5]. After summing up the study, it was noticed that the interaction between biochar and the MSW was not provided. Wang et al. (2012) reported that the calorific value of rice husk was bolstered by $26 \%$, while it was $57 \%$ for sugarcane during micro-wave torrefaction. They had seen that the size, processing time and heat flux had a phenomenal impact on the torrefaction process [6]. The wheat and barley straw in a microwave heating system was carbonised owing to microwave irradiance, which merely increased the energy density by $14-15 \%$ [7]. The various studies on the similar technique were conducted, but the effect of temperature was not clearly stated nor was its effect on physical traits of biomass explained [8]-[13]. From literature review, it was clear that the microwave heating system requires surplus power to produce a desirous effect. Moreover, the generated gas cannot be recycled for further process. The practical application of this work is to determine temperature and flux distribution while the pellet undergoes a torrefaction at quasi-static condition of the modified muffle furnace. With the help of distribution, it could be figured out whether modified muffle furnace is able to maintain homogeneity during the torrefaction process or not. Since most of the torrefaction technologies [14] lag to impart a homogenous distribution of temperature or heat flux across the biomass.

This work focused on the thermal modelling of raw pinecones pellets subjected to quasistatic torrefaction in a resistivity heating system. The effect of thermal profile and thermofluid properties of inert gas on temperature distribution of pellet was examined by the pdepe technique.

\section{MATERIAls AND MethodS}

The experiments were conducted at National Agriculture and Innovation Centre, Hungary. The raw pine cones (Austrian pine) were collected from Pest county of Hungary. Before processing the raw feedstock, it was sundried for two days. In the subsequent sections, the fuel processing along with the technique used to analyse thermal processed material are discussed.

\subsection{Fuel Preparation and Thermal Pre-Treatment}

The net $4 \mathrm{~kg}$ of pine cones was processed under the pilot scheme (Fig. 1). Before milling the feedstock, it was sundried for 2 days, so that the plastic flow might hamper the milling process. The 3-phase (star-connection), heavy duty, $1.5 \mathrm{~kW}$ rotor milling machine (6-disc rotor) (Retsch SM 2000, Germany) was employed for the same. The fed rate was selected to be $200-300 \mathrm{~g} \mathrm{~h}^{-1}$ to prepare the material for pelletisation. The selected sieve of $1.5 \mathrm{~mm}$ was used for the refining process. Upon finishing the milling process, the moisture content of the feedstock was examined so as to measure whether the material has an adequate water content for binding or not. During the initialisation process, the pellet machine was heated up to $343 \mathrm{~K}$. The quality of produced pellet also depends on the pressure required by the material and the geometry of the die used. Therefore, it is necessary to examine temperature of the die and pellet sporadically. The compacting of the feedstock was performed using a ring die (CL3, 
California Pellet Mill, USA) (Fig. 2). Before beginning the screw extrusion, the fine powder was allowed to feed into a barrel. The objective of the screw auger is to push the material into the chamber where one to three rollers press the material in a radially outward direction. The geometrical length and diameter of the selected die were $25.95 \mathrm{~mm}$ and $4.83 \mathrm{~mm}$, respectively. The die temperature was noticed to be increased from $333 \mathrm{~K}$ to $363 \mathrm{~K}$, whereas the finished pellet was at $313-327 \mathrm{~K}$. The challenges faced during pelletisation are often related to binding ability and the resilience against compression, whereas the surface quality of the die, the rotation speed, and the material of die are the secondary factors.

Once the densification was completed, the pinecones were systematically fed into an improvised torrefaction unit at $523 \mathrm{~K}$ for holding time of 5, 10, and 15 minutes. The indirect heating of pine cones was based upon the resistive heat capacity of the furnace (Nabertherm, P320 Controller, Germany) (Fig. 3). The energy consumption/heat flux during the process was measured with the help of the Energy logger (Voltcraft 4000, Germany). The digitally programmed furnace was modified by replacing the conventional lid with a modified ones which accommodates a cylinder with a ram, inert gas ducts, cooling fan, feeder and the holding vessel for the pellets. To record the mass variation, the vessel has been mechanically connected to the weighing machine. The volumetric flow rate of nitrogen was considered to be $700 \mathrm{~mL} \mathrm{~min}^{-1}$. It is to be noted that the excessive flow of inert gas increases the heating load and influence thermal equilibrium, which was considered in the study with the help of Nusselt number. The operating pressure inside the vessel was maintained at $1.5 \mathrm{bar}$. The gas flow was measured with help of a diaphragm type gas meter (Ganz 2000, Hungary).

The elemental composition of feedstock was estimated by a CHNS analyser (Vario MACRO Elementar). A standard birch leaf sample was used to calibrate the apparatus. As a catalyst Tungsten (VI) oxide was used to facilitate the complete oxidation of the samples. The readings were repeated thrice, and the average value was taken. In the starting, the analyser was heated up to $1473 \mathrm{~K}$ for 30 minutes. Once the pre-oxidation temperature was reached, the encapsulated samples were fed into the chamber via a rotating turret mounted on the analyser. The helium gas was brought into use to carry away the product of combustion into their respective reduction columns. The elements of gas were separated through a purge or trap chromatography, which were later determined by a thermal conductivity detector (TCD) (Fig. 4). The heating value of pinecones was measured with the help of the oxygen bomb calorimeter (IKA WERKE C2000). A standard benzoic tablet was used to calibrate the calorimeter. The permissible working pressure of the calorimeter was not allowed to exceed $23 \mathrm{MPa}$, whereas the oxygen was kept below $4 \mathrm{MPa}$. The temperature of water in the water tub was heated up to $298 / 303 \mathrm{~K}$ before starting the calibration process. The elemental, as well as physical composition, of pinecones, are provided in Table 1 and Table 2, respectively.

TABle 1. The ElEMENTAl Characteristic OF PINECONES

\begin{tabular}{lllllllll}
\hline $\mathrm{C} \%$ & $\mathrm{H} \%$ & $\mathrm{~N} \%$ & $\mathrm{O} \%$ & $\mathrm{~S} \%$ & Ash \% & FC \% & $\mathrm{VC} \%$ & $\mathrm{HHV}\left({\left.\mathrm{MJ} \cdot \mathrm{kg}^{-1}\right)}\right.$ \\
\hline 48.62 & 5.31 & 0.94 & 44 & 0.10 & 1.22 & 18.42 & 80.355 & 20.14 \\
\hline
\end{tabular}

Table 2. The Physical Characteristics of the Pinecones Pellet

\begin{tabular}{lllll}
\hline$\rho_{\mathrm{b}}, \mathrm{kg} \cdot \mathrm{m}^{-3}$ & Length, $\mathrm{mm}$ & Diameter, $\mathrm{mm}$ & Energy density, $\mathrm{GJ} \cdot \mathrm{m}^{-3}$ & $\rho_{\mathrm{m}}, \mathrm{kg} \cdot \mathrm{m}^{-3}$ \\
\hline 681 & 19.42 & 4.90 & 19.47 & 1151 \\
\hline
\end{tabular}




\subsection{Finite Element Analysis}

The ordinary heat transfer equation was solved using pdepe in MATLAB2015a. The effect of conduction and convection on temperature distribution was only studied. The different value of Nusselt and Reynold numbers of nitrogen flow was used to examine the effect of inert medium on the pinecone pellet. The effect of porosity was considered to be negligibly small. The 2-D conduction equation was considered at a varying heat flux. The effect of surface irregularity along the top and bottom surfaces were excluded during the simulation. The mixed boundary condition was applied during the computation process. The thermal/heat transfer parameters related is provided in Table 3.

TABle 3. The Thermal / Heat Transfer Parameters For A Pinecone Pellet

\begin{tabular}{lllll}
\hline$C, \mathrm{~kJ} \cdot \mathrm{kg}^{-1} \cdot \mathrm{K}^{-1}$ & $k, \mathrm{~W} \cdot \mathrm{m}^{-1} \cdot \mathrm{K}^{-1}$ & $\overline{\boldsymbol{h}}, \mathrm{W} \cdot \mathrm{m}^{-2} \mathrm{~K}^{-1}$ & $N u$ & $R e$ \\
\hline 3.51 & 11.27 & 2.55 & 0.00439 & 798.85 \\
\hline
\end{tabular}

The heat equation used for determining temperature distribution across the pellet was given by the following equation:

$$
\rho_{m} C \frac{\partial T}{\partial t}-\nabla \cdot(k \nabla T)=Q+h\left(T_{e x t}-T\right)
$$

The generalised Neumann and Dirichlet boundary conditions applied at the interface are provided by

$$
\hat{n} \cdot k \nabla T+h T=g
$$

and

$$
J \cdot T=r .
$$

Here, $g$ is the heat flux $\left(\mathrm{W} \cdot \mathrm{m}^{-2}\right)$ and $h\left(\mathrm{~W} \cdot \mathrm{m}^{-2} \mathrm{~K}^{-1}\right)$ is the heat transfer coefficient of a thin film of nitrogen gas around the surface. On the other hand, $J$ and $r$ are the arguments at the surface of the pellet.

The heat transfer coefficient $(\bar{h})$ of the nitrogen gas inside the furnace is estimated from Churchill and Bernstein correlation (Valid for $100<\operatorname{Re}<10^{7}$ and $\operatorname{Re} \cdot \operatorname{Pr}>0.2$ ) [15].

$$
\bar{h}=\frac{k}{L}\left[0.3+0.62 \frac{(\operatorname{Re})^{0.5}(\operatorname{Pr})^{0.33}}{\left(1+\left(\frac{0.4}{\operatorname{Pr}}\right)^{0.66}\right.}\left(1+\left(\frac{R e}{28200}\right)^{0.625}\right)^{0.8}\right]
$$

Here, $L$ is the characteristic length of the biofuel pellet.

The thermal conductivity based on moisture and specific gravity of pellet is determined by the following empirical formula [16].

$$
k=S(7.88+0.158 M \%)+0.93
$$




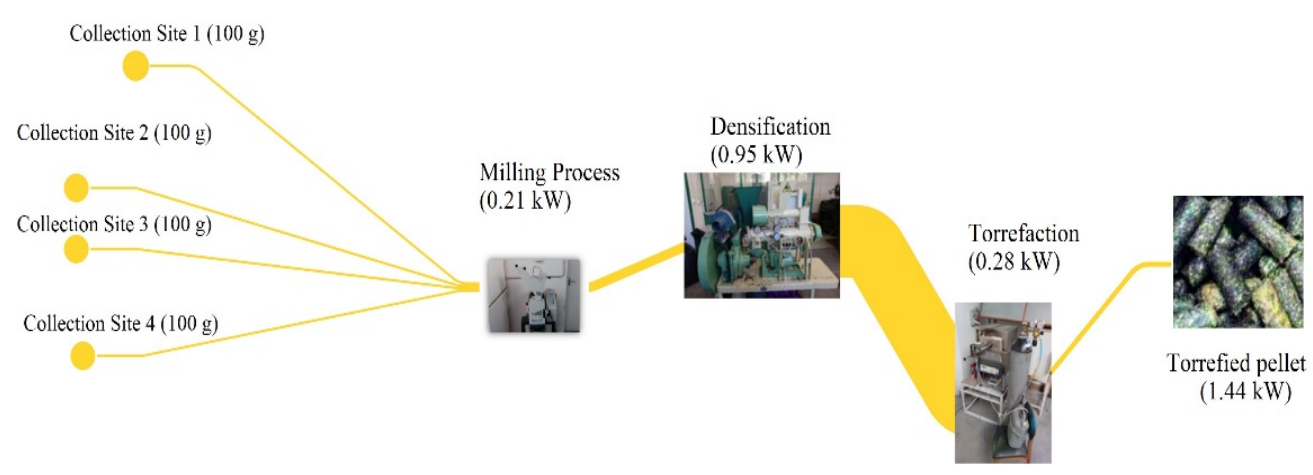

Fig. 1. The process flow diagram of the raw pine cones along with energy consumption.

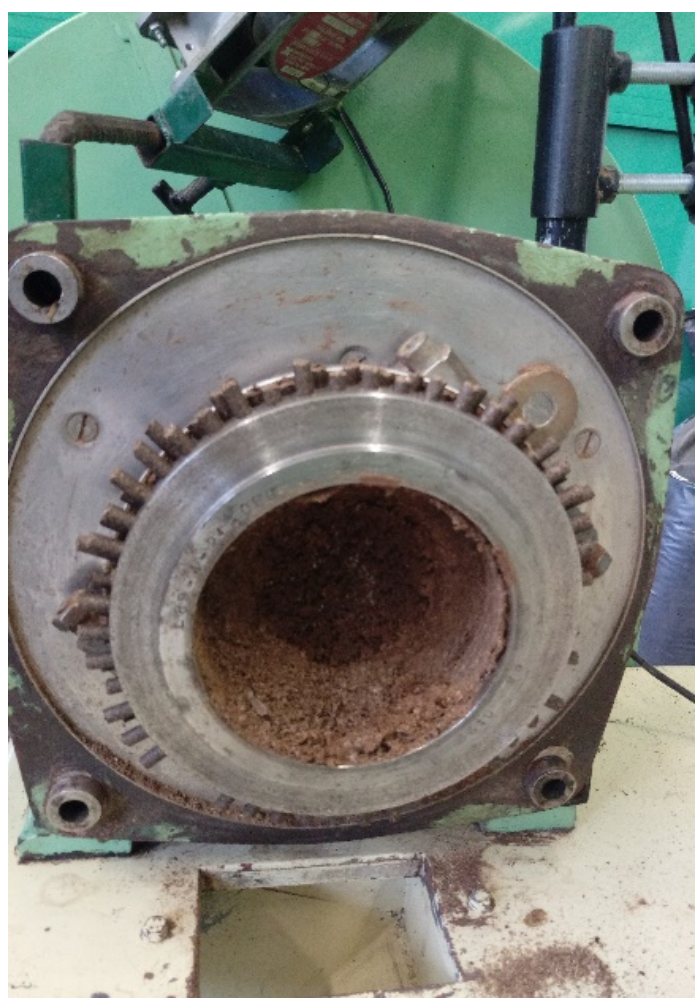

Fig. 2. The ring-die for the densification process. 


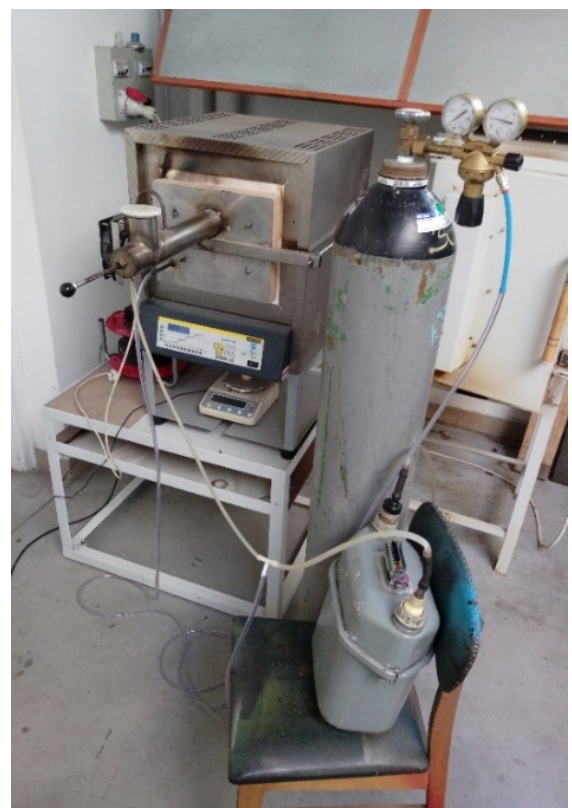

(a)

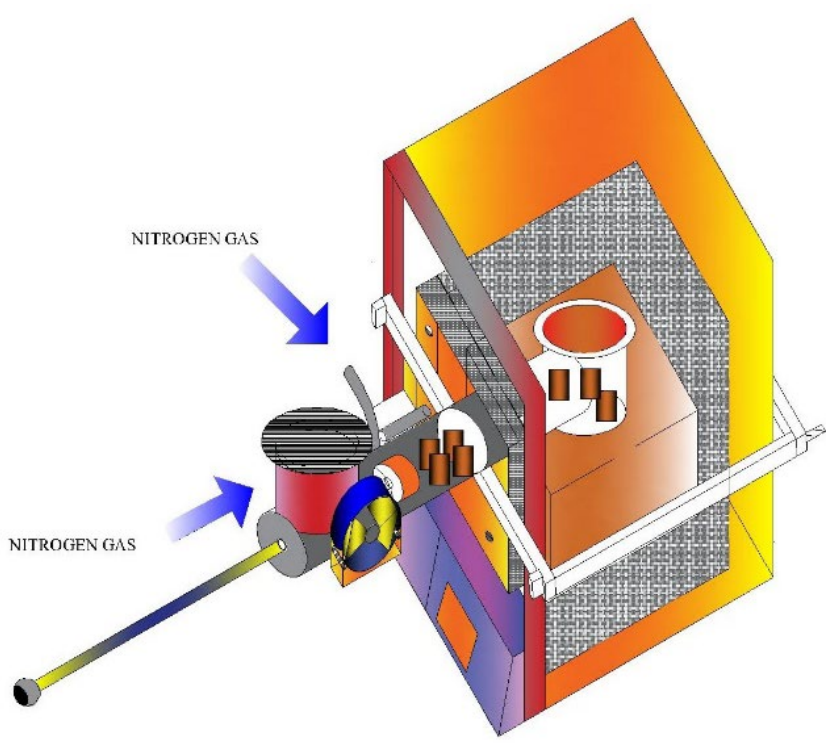

(b)

Fig. 3. The modified furnace used for thermal pre-treatment: a) Joule Heating System; b) Technical drawing of the torrefaction unit. 


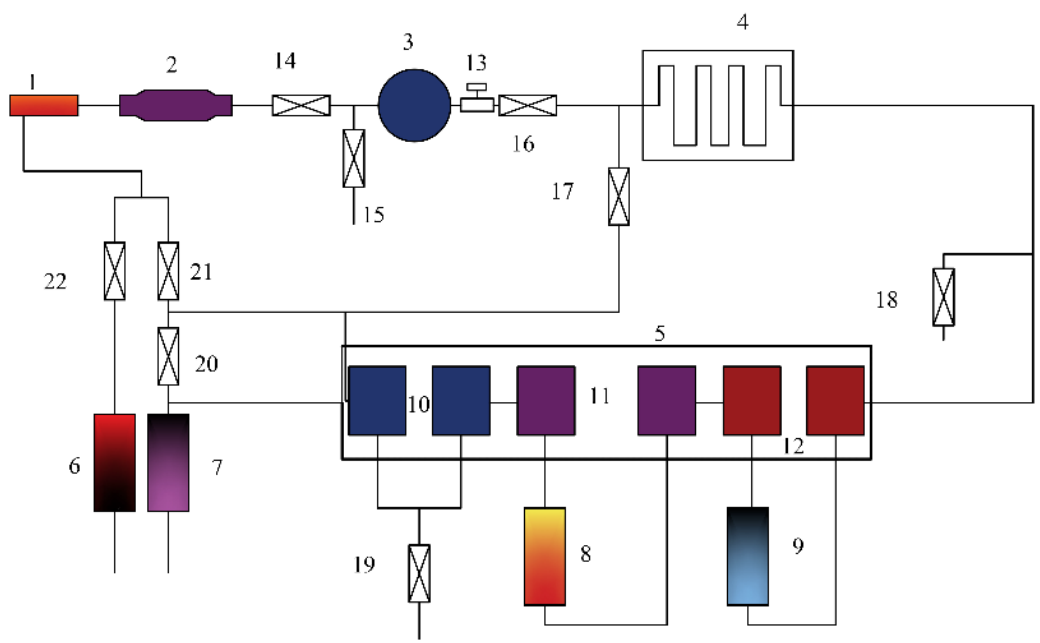

Fig. 4. The flow schematic diagram of CHNS analyser: 1) Combustion tube; 2) Reduction tube; 3) Mixing Volume; 4) Sample volume; 5) Thermal conductivity detector; 6) Scrubber (Oxygen supply); 7) Scrubber (Helium supply); 8) $\mathrm{CO}_{2}$ trap; 9) $\mathrm{H}_{2} \mathrm{O}$ trap; 10) Nitrogen capture; 11) Carbon capture; 12) Hydrogen capture; 13) Pressure transducer; 14) Cut-off valve between the combustion train and the analytical system; 15 and 16) Purge valve; 17) Exhaust valve; 18) Gas control valve; 19 and 20) Automatic leak testing valves: 21) Solenoid valve; 22) Oxygen flow control valve.

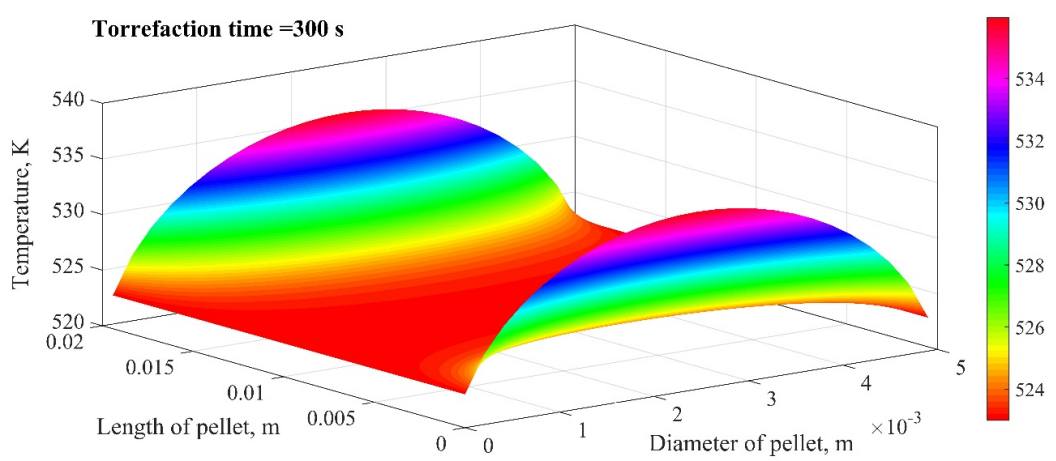

(a)

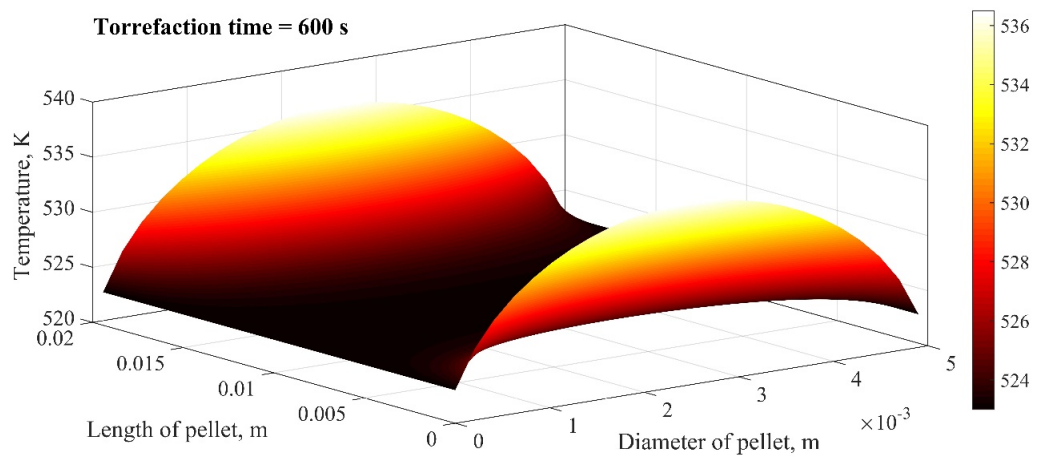

(b) 


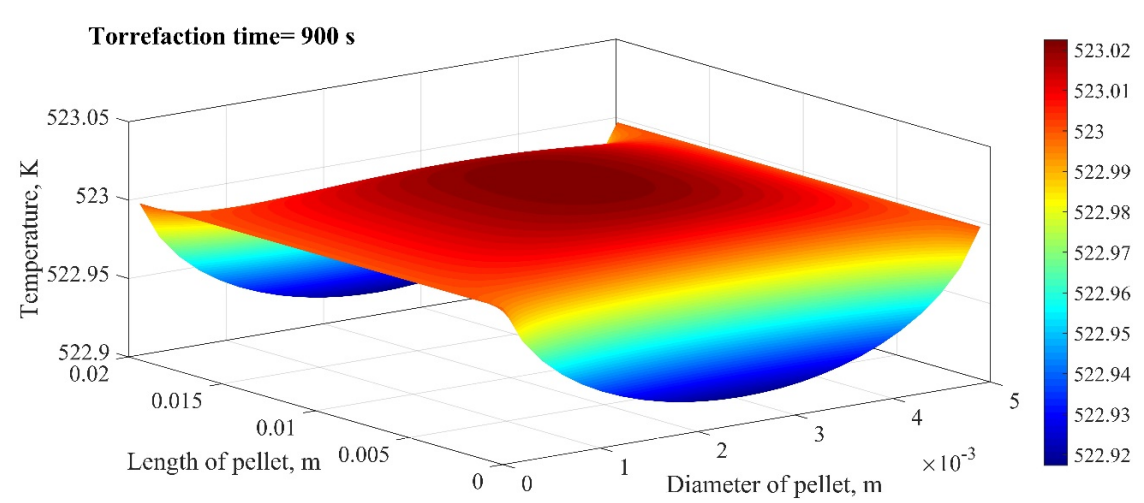

(c)

Fig. 5. The effect of varying heat flux and processing time on the temperature distribution across the pellet: a) $81.55 \mathrm{~kW} \cdot \mathrm{m}^{-2}$; b) $84.88 \mathrm{~kW} \cdot \mathrm{m}^{-2}$; c) $86.068 \mathrm{~kW} \cdot \mathrm{m}^{-2}$.

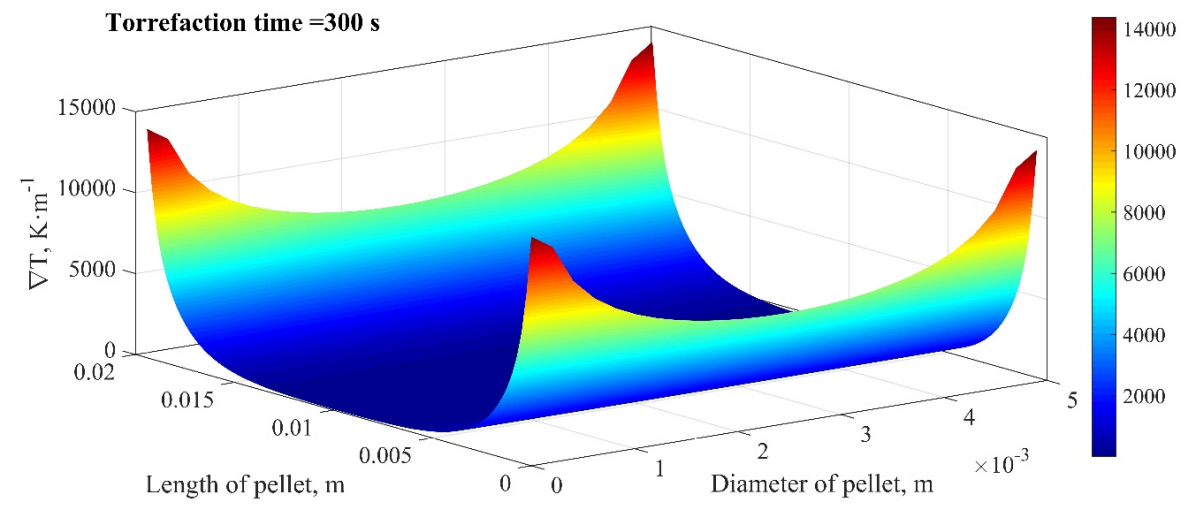

(a)

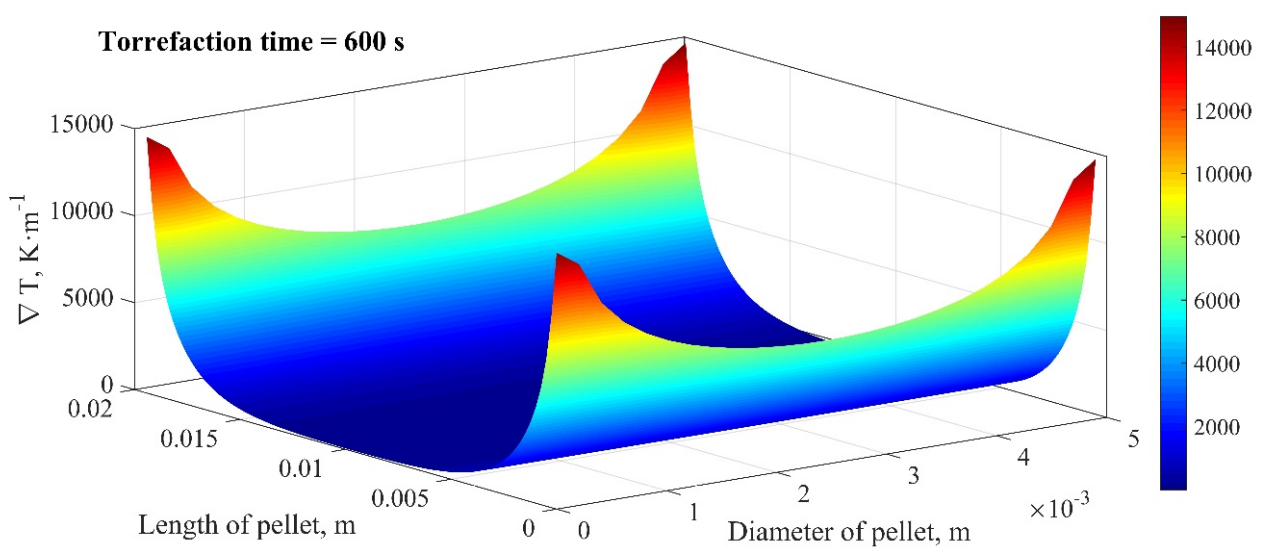

(b) 


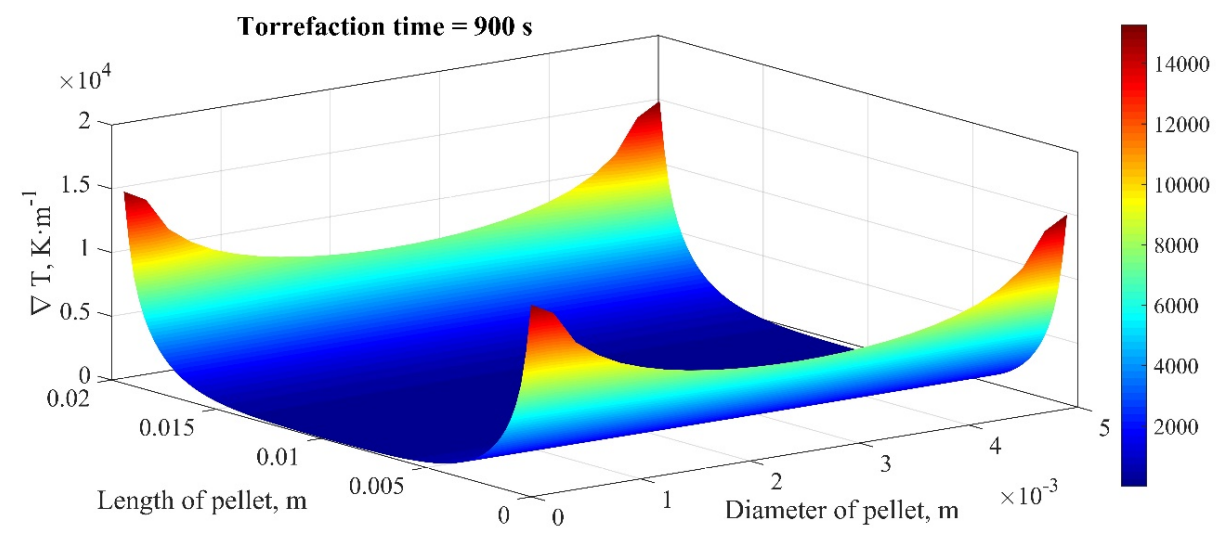

(c)

Fig. 6. Variation in the temperature gradient across the pellet: a) $81.55 \mathrm{~kW} \cdot \mathrm{m}^{-2}$; b) $84.88 \mathrm{~kW} \cdot \mathrm{m}^{-2}$; c) $86.068 \mathrm{~kW} \cdot \mathrm{m}^{-2}$.

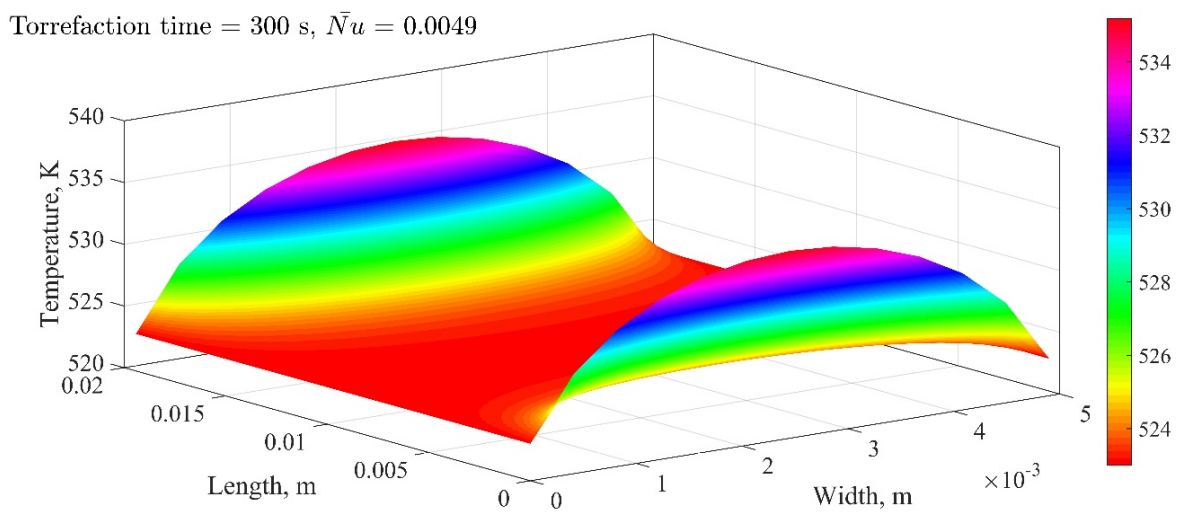

(a)

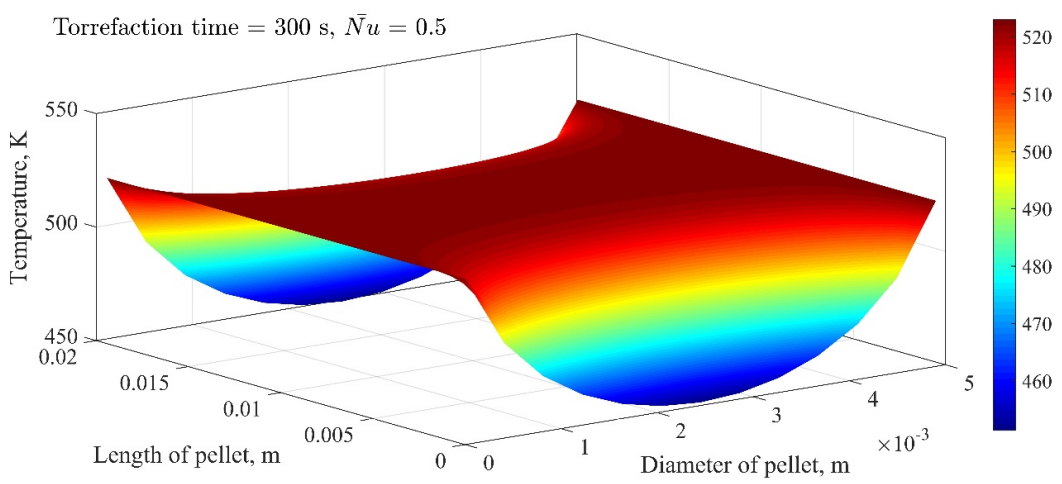

(b) 


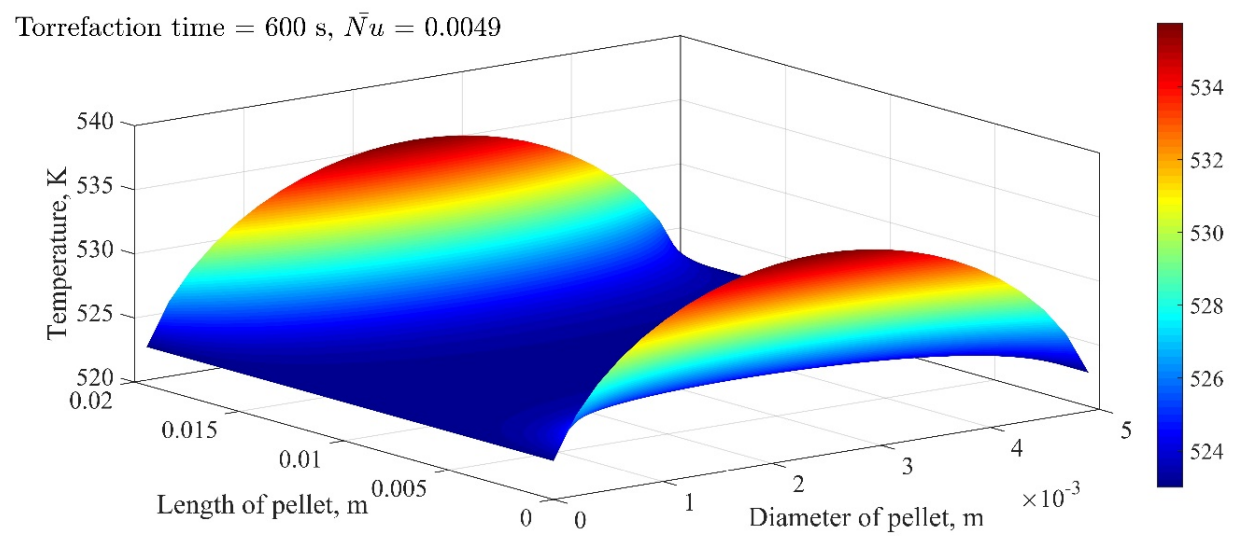

(c)

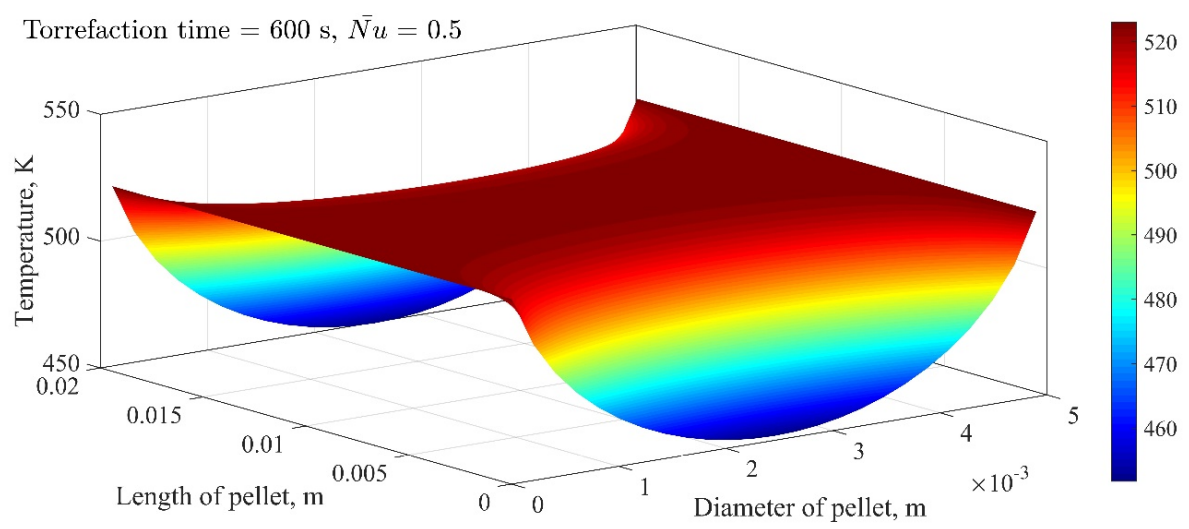

(d)

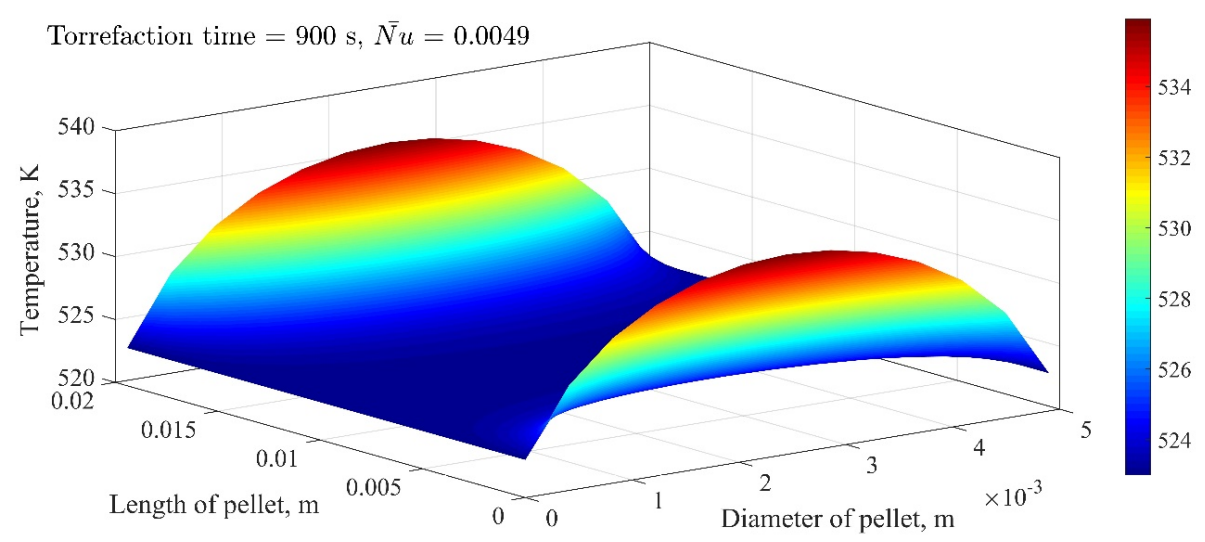

(e) 


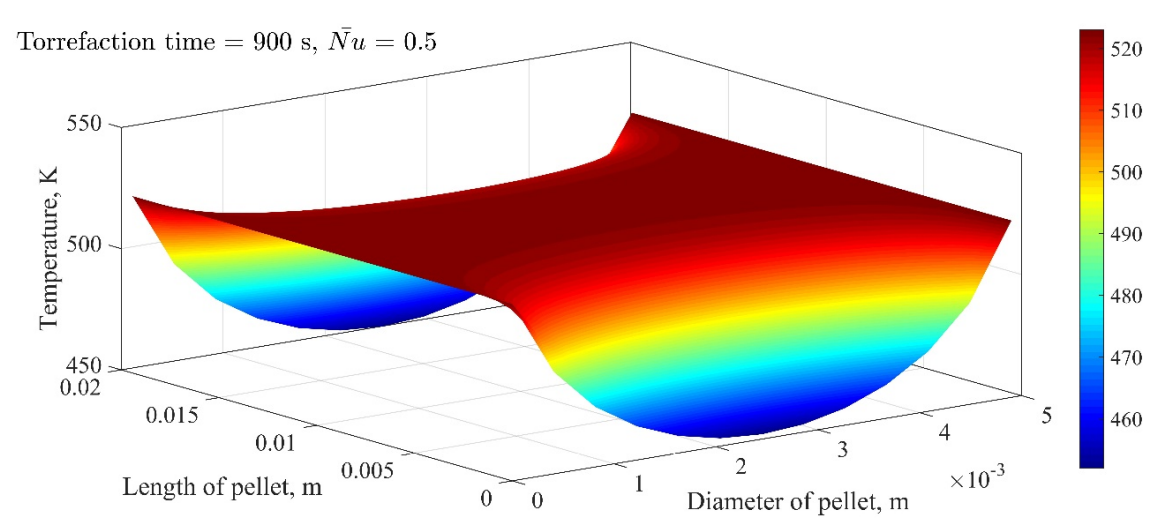

(f)

Fig. 7. The effect of Nusselt number on the temperature distribution: a-b) $81.55 \mathrm{~kW} \cdot \mathrm{m}^{-2}$; $\left.\mathrm{c}-\mathrm{d}\right) 84.88 \mathrm{~kW} \cdot \mathrm{m}^{-2}$; e-f) $86.068 \mathrm{~kW} \cdot \mathrm{m}^{-2}$.

\section{Results AND DiscusSiON}

Temperature distribution across pinecone pellet upon the torrefaction in the Joule heating system was examined with the help of finite element analysis. The effect of processing time along with the varying heat flux is shown in Fig. 5. Having seen the numerical solution, it was concluded that the temperature along the diametrical axis of the pellet would increase by $0.37 \%$ at the core of pellet as the heat flux is elevated by $4.10 \%$. Similarly, the temperature would lie in domain of 524-526 K along the traverse axis of the biofuel pellet. A surge of $2.1-2.5 \%$ above the furnace temperature was estimated at interior region of pellet, whereas it was around a $0.19-0.57 \%$ rise computed at top and bottom section of pellet. The reason for this rise could be due to increasing thermal diffusivity across the pellet that allows a rapid change in temperature at the interior region of the pellet. The deviation in the temperature range at bottom of pellet was found to be symmetrical with the temperature zone obtained at the top of the pellet. The finite element analysis showed a homogeneous distribution of temperature along the mid-section of the pellet. A paraboloid thermal distribution was noted down at the vicinity of the base and the top of pellet. A linear shift in the dome of paraboloid along the traverse was seen. As the processing time increasing the curvature of the paraboloid was found to be shifted towards the centre of cylindrical pellet, which implies the processing time would allow the dome to merge and allow the core of the pellet to reach the base or top temperature with time (i.e., symmetricity of temperature distribution at interior part of the pellet would change with increasing processing time and heat flux). A traverse shift of 34.40 $51.72 \%$ was computed along the centre axis and the eccentricity of the temperature profile would reduce. In other words, temperature distribution would be pushed to attain a steady state and it would rely only on the directional gradient or geometrical shape and size of the pellet. However, with further increase in the processing duration, the change in temperature along the length of the pellet gets slower and the pellet temperature approaches a stagnant stage. It implies the higher processing time and flux rate would have major impact at circumferential location of the pellet rather than the interior region of the pellet. The corresponding thermal gradient is illustrated in Fig. 6. 
The thermal gradient firmly supported the assertion provided for temperature distribution along the diametrical and transverse axes. The circumferential location was seen to experience the highest rate of change of thermal gradient. With the increase in the processing time and heat flux, the thermal gradient was also soared by $50 \%$ and it would tend to be attain uniformity at the base and top of the pellet. The drift would be the highest at the diametrical ends of the pellet and the interior region tending to approach the circumferential value with time. There was not much quantitative drift was seen in the temperature gradient except the attribute of the paraboloid, which in itself speak volumes about the thermal characteristic of pellet. The temperature gradient at the centre of the base was found to be surged by $48 \%$ while increasing the heat flux by $4.10 \%$, whereas it was dropped by $49 \%$ upon further increasing the duration of the torrefaction process from $600 \mathrm{~s}$ to $900 \mathrm{~s}$. On the other hand, a rise of 4.14-5.60\% in thermal gradient was computed for 300-900 s at the top surface of the pellet. Relatively to the diametrical axis, the increase in thermal gradient was noticed to be reduced by $2.44-3.18 \%$. However, with increasing torrefaction time, the rise in thermal gradient had been encountered along both the directions, but the change in thermal attribute was phenomenal along with the thickness of the pellet. The negative displacement of $8.33 \%$ was estimated in the global minima when the torrefaction time was increased by $300 \mathrm{~s}$. As time proceed, it was increased by the $8.32 \%$. The displacement of minima indicated nonhomogenous distribution of heat flux across the azimuth plane. It is to be noted that thermal and fluid were not changed while simulating the thermal behaviour of pinecones pellets in Fig. 5 and Fig. 6.

The effect of Nusselt number of nitrogen flow on temperature distribution is shown in Fig. 7. As it can be seen the increase in the Nusselt number $(\mathrm{Nu})$ change the morphology of the thermal pattern. The temperature along transverse axis is drop by $2.69 \%$, while it was reduced by $2.69-14 \%$ along the diametrical axis of the pellet. The temperature at the centre region of pellet was dropped by $15.65 \%$ while processing pellet for $300 \mathrm{~s}$ at varying Nusselt number of the inert gas. Similarly, it was $-15.68 \%$ during the thermal pre-treatment of pinecone pellet for $600 \mathrm{~s}$, and $-15.65 \%$ when the similar pellet torrefied for $900 \mathrm{~s}$. It could be seen the effect of Nusselt number was marginally reduced upon increasing the processing time. However, it was got pretty much constant at the end of the torrefaction process. The furnace temperature was found to be change by $-3 \mathrm{~K}$ to $11 \mathrm{~K}$ when $N u$ of gas flow was changed. The rise in Nusselt number made the temperature distribution more uniform with the increase in time, whereas the reduction in the convective rate of heat transfer allowed the pellet for heterogeneous distribution of temperature across of the pellet and with increasing time, it would approach to a thermal equipotential surface. It can be concluded the rise in Nusselt number would allow the pellet to attain thermal equilibrium much faster than that with increasing the processing time.

\section{Conclusion}

This work focussed on the heat transfer analysis of the biofuel pellet which underwent thermal pre-treatment at constant temperature for varying time interval. From the study, it was found that thermal characteristic of pellet would be drastically changed when it was pre-treated at varying heat flux for different processing time. It was estimated that temperature was surged by $0.37 \%$ at the core of the pellet when the heat flux was allowed to vary from $81.55 \mathrm{~kW} \cdot \mathrm{m}^{-2}$ to $86.068 \mathrm{~kW} \cdot \mathrm{m}^{-2}$. Similarly, it was 2.1 to $2.5 \%$ at the interior region of the pellet. The effect of processing time allowed the pellet to attain a thermal equipotential along the dimension of pellet. Thermal gradient was elevated by $50 \%$ at the end of the torrefaction process. The temperature gradient was estimated to be dropped by $48 \%$ along the centre axis of pellet. The 
spatial characteristic was merely seen with time rather than a quantitative deviation in the thermal gradient. With the increase in the processing time and heat flux, the thermal gradient was also soared by $50 \%$ and it would tend to be attain uniformity at the base and top of the pellet. The drift would be the highest at the diametrical ends of the pellet and the interior region tending to approach the circumferential value with time. There was not much quantitative drift was seen in the temperature gradient except the attribute of the paraboloid, which in itself speak volumes about the thermal characteristic of pellet. The temperature gradient at the centre of the base was found to be surged by $48 \%$ while increasing the heat flux by $4.10 \%$, whereas it was dropped by $49 \%$ upon further increasing the duration of the torrefaction process from $600 \mathrm{~s}$ to $900 \mathrm{~s}$. A time-varying shift in local maxima was noticed with the change in the heat flux. Likewise, the morphological change in temperature plane was noticed when the Nusselt number of inert gas was increased. The temperature along the length of pellet was reduced by $2.69 \%$, whereas it was $2.69-14 \%$ along the thickness of the pellet. The furnace temperature was noticed to be dropped by $3 \mathrm{~K}$ when the Nusselt was increased to 0.5 . However, at the starting of simulation, the temperature was found to be drastically reduced by $15.65-15.68 \%$, but with time, a temperature uniformity was attained. From the given analysis, it was found that the increasing torrefaction time brought a marginal change in temperature distribution along the diametrical as well as longitudinal axes. However, the drastic variation in a temperature gradient, heat flux and temperature distribution would have occurred in a modified muffle furnace if the heat transfer characteristic of the torrefaction medium had changed. However, the drastic variation in temperature gradient, heat flux and temperature distribution would be occurred in modified muffle furnace when heat transfer characteristic of torrefaction medium gets changed. The proposed furnace had successfully provided homogeneity, but the flow of medium caused a drastic deviation in the temperature across the pellet. It could be better if the different media are used for torrefaction in the proposed model as it is not essential all the gases behave similarly as Nitrogen did in the Joule heating system.

\section{REFERENCES}

[1] Zhi W. J., Wang L. F., Hu X. J. Recent advances in the effects of microwave radiation on brains. Military Medical Research 2017:4(1):29. https://doi.org/10.1186/s40779-017-0139-0

[2] Huang Y. F., et al. Microwave torrefaction of sewage sludge and Leucaena. Journal of the Taiwan Institute of Chemical Engineers 2017:70:236-243. https://doi.org/10.1016/j.jtice.2016.10.056

[3] Huang Y. F., et al. Co-torrefaction of sewage sludge and leucaena by using microwave heating. Energy 2016:116:17. https://doi.org/10.1016/j.energy.2016.09.102

[4] Yu K. L., et al. Bioethanol production from acid pretreated microalgal hydrolysate using microwave-assisted heating wet torrefaction. Fuel 2020:279:118435. https://doi.org/10.1016/j.fuel.2020.118435

[5] Siritheerasas P., et al. Torrefaction of Municipal Solid Waste (MSW) Pellets using Microwave Irradiation with the Assistance of the Char of Agricultural Residues. Energy Procedia 2017:138:668-673. https://doi.org/10.1016/j.egypro.2017.10.190

[6] Wang M. J., et al. Microwave-induced torrefaction of rice husk and sugarcane residues. Energy 2012:37(1):177-184. https://doi.org/10.1016/j.energy.2011.11.053

[7] Satpathy S. K., et al. Torrefaction of wheat and barley straw after microwave heating. Fuel 2014:124:269-278. https://doi.org/10.1016/j.fuel.2014.01.102

[8] Yek P. N. Y., et al. Microwave wet torrefaction: A catalytic process to convert waste palm shell into porous biochar. Materials Science for Energy Technologies 2020:3:742-747. https://doi.org/10.1016/j.mset.2020.08.004

[9] Negi S., et al. Torrefaction: a sustainable method for transforming of agri-wastes to high energy density solids (biocoal). Reviews in Environmental Science and Biotechnology 2020:19:463-488. https://doi.org/10.1007/s11157$\underline{020-09532-2}$

[10] Dhaundiyal A., etal. Comprehensive analysis of pre-treated Austrian pine. Fuel 2021:287:119605. https://doi.org/10.1016/j.fuel.2020.119605 
[11] Dhaundiyal A., Singh S. B., Toth L. Experimental investigation of a small-scale reactor with processed bio-fuel pellets. Biofuels, Bioproducts and Biorefining 2021:15(5):1496-1519. https://doi.org/10.1002/bbb.2256

[12] Dhaundiyal A., et al. Development of a Small-scale Reactor for Upgraded Biofuel Pellets. Renewable Energy 2021:170:1197-1214 https://doi.org/10.1016/j.renene.2021.02.057

[13] Dhaundiyal A., Bercesi G., Backsai I. The effect of torrefaction on the thermo-kinetics of thermally processed black pine. The Canadian Journal of Chemical Engineering 2020:99(10):2241-2256. https://doi.org/10.1002/cjce.23933.

[14] Dhungana A., Basu P., Dutta A. Effects of Reactor Design on the Torrefaction of Biomass. Journal of Energy Resources Technology 2012:134(4)1-11. https://doi.org/10.1115/1.4007484

[15] Holman, J. P. Heat transfer. 9th Edition. New York, Boston: McGraw-Hill, 2002.

[16] MacLean J. D. Thermal conductivity of wood. Heating, piping \& air conditioning. Madison: USA, 1941. 